\title{
AVALIAÇÃO DA PRODUTIVIDADE DAS SILAGENS DE GIRASSOL, MILHO, SORGO E MILHETO EM DIFERENTES ESPAÇAMENTOS
}

\author{
TEIXEIRA, Fabrício Antônio ${ }^{1}$ \\ AMIN, Willian Garofo ${ }^{1}$ \\ MELLO, Sílvio de Paula ${ }^{2}$
}

Recebido em: 2009-03-25

Aprovado em: 2009-08-10

ISSUE DOI: $10.3738 / 1982.2278 .184$

RESUMO: O trabalho experimental foi conduzido no Campus da FAFRAM, Faculdade "Dr. Francisco Maeda", localizada no município de Ituverava, SP, no período de 14 de novembro de 2007 a 12 de fevereiro de 2008, com o objetivo de avaliar a produtividade de matéria verde nas culturas de girassol, milho, milheto e sorgo em diferentes espaçamentos, para silagem. O delineamento experimental foi o de blocos ao acaso em um esquema fatorial 4 x 4 com duas repetições. Cada parcela foi constituída por três metros lineares, com espaçamentos de 0,50, 0,60, 0,70 e 0,80 metros. Os resultados foram significativos para o peso do colmo, peso do capítulo e peso total de matéria verde (PTMV) na cultura do girassol. Já para o peso da folha observou-se diferença significativa para a cultura do milho. Nos espaçamentos de 0,60, 0,70 e 0,80 metros, os pesos de colmo, espiga, panícula e PTMV não apresentam diferenças significativas. Já para o peso de folha, o espaçamento de 0,80 proporcionou melhor média. Quanto ao peso do colmo nas culturas de girassol, milheto, milho e sorgo nos espaçamentos de 0,50, 0,60, 0,70 e 0,80 m, obtiveram resultados significativos nos quatro espaçamentos a cultura do girassol registrando $28.166,66 \mathrm{Kg}$, $31.526,51 \mathrm{Kg}, 43.450,20 \mathrm{Kg}$ e $39.062,49 \mathrm{Kg}$ respectivamente. Concluiu-se que a produção total de massa verde para a cultura do girassol, milheto e milho foi maior com o espaçamento de $0,80 \mathrm{~m}$, enquanto a cultura do sorgo a produção foi maior com o espaçamento de 0,60 metros.

Palavras-chave: Silagens. Produtividade. Espaçamentos.

SUMMARY: The experimental work was conducted on the campus of FAFRAM, Faculty "Dr. Francisco Maeda ", located in the municipality of Ituverava, SP, in the period from November 14, 2007 to February 12, 2008, aiming to evaluate the productivity of green matter on crops of sunflower, corn, millet and sorghum in different spacings, for silage. The experimental design was a randomized blocks in a factorial $4 \mathrm{x} 4$ with two replications. Each plot was formed by three meters, with spacing of $0,50,0,60,0,70$ and 0,80 meters. The results were significant for the weight of the stem, weight of the chapter and total weight of green matter (PTMV) in sunflower cultivation. For the weight of the sheet was a significant difference for corn. In spacing of 0,60, 0,70 and 0,80 meters, the weights of Stockholm, ear, panicle and PTMV not have significant differences. For the weight of leaf, the spacing of 0,80 provided better average. As the weight of the stem on crops of sunflower, millet, maize and sorghum in the spacing of $0,50,0,60$, 0,70 and $0,80 \mathrm{~m}$, obtained significant results in the four spacing the culture of sunflower registering $28.166,66 \mathrm{~kg}$, $31.526,51 \mathrm{~kg}, 43.450,20 \mathrm{~kg}$ and $39.062,49 \mathrm{~kg}$ respectively. It was concluded that the total production of green mass for the cultivation of sunflower, millet and corn was higher with the spacing of 0,80 meters, while the cultivation of sorghum production was higher with the spacing of 0,60 meters.

Keywords: Silage. Productivity. Spacings.

\footnotetext{
${ }^{1}$ Engenheiro Agrônomo.

${ }^{2}$ Zootecnista. Doutor em Genética e Evolução. Professor titular na FE/FAFRAM/FFCL
} 


\section{INTRODUÇÃO}

A silagem é o produto obtido pela fermentação anaeróbica da forragem, conservando o volumoso para ser utilizado no período crítico de produção dos pastos, ou seja, na seca. Uma vantagem das silagens é a exigência de uma tecnologia simples e eficiente. Embora não necessite de tecnologias complexas para o processo de ensilagem, este tem que ser feito com alguns cuidados, para se manter o valor nutritivo da forragem (AGROINFO, 2007).

Gonçalves; Tomich (2000) afirmam que, na maioria das áreas agrícolas do mundo, períodos de intenso crescimento forrageiro alternam-se com períodos de baixa produção, seja por geada ou por seca. Uma prática para melhorar a alimentação do rebanho e minimizar os efeitos da redução de peso e produção de leite é a conservação de forragens, via ensilagem.

O milho (Zea mays L.) é a espécie forrageira mais utilizada para a ensilagem. Entretanto, outras culturas, por se adaptarem melhor as condições climáticas e de solo menos favoráveis, têm sido recomendadas, como o sorgo (Sorghum bicolor (L). Moench) e o girassol (Helianthus annus L.) (POSSENTI, 2005).

A cultura do sorgo para a ensilagem vem crescendo e representa grande percentual da área total cultivada para silagem no Brasil. Segundo os mesmos autores, as principais justificativas para a crescente expansão da cultura do sorgo no país foram altas produções por hectare; bom valor nutritivo ( $72 \%$ a $92 \%$ do valor nutricional da silagem de milho); tolerância a déficits hídricos ocasionais e possibilidade de rebrota.

O girassol (Helianthus annuus L.) é uma alternativa para silagem, pois se desenvolve bem em climas temperados, subtropical e tropical. Possui, também, maior tolerância à deficiência hídrica e geadas leves, quando comparado com o milho e o sorgo. A silagem de girassol apresenta como vantagens o alto valor energético e o teor de proteína, que pode ser $35 \%$ superior ao do milho (GONÇALVES; TOMICH, 2000).

A silagem de girassol apresenta composição bromatológica distinta à silagem de milho ou sorgo, com maior teor de proteína bruta e extrato etéreo (POSSENTI, 2005).

Quanto ao potencial produtivo do milheto, pode alcançar até 60 toneladas de massa verde e 20 toneladas de matéria seca por hectare, quando cultivado no início da primavera (RIBEIRO, 2002).

O objetivo do trabalho foi avaliar a produtividade de matéria verde nas culturas de girassol, milho, milheto e sorgo, em diferentes espaçamentos, para silagem.

Nucleus, v.6, n.2, out. 2009 


\section{REVISÃO DA LITERATURA}

É chamada silagem a forragem verde, suculenta, conservada por meio de um processo de fermentação anaeróbica. As silagens são guardadas em silos. Chama-se ensilagem o processo de cortar a forragem, colocá-la no silo, compactá-la e protegê-la com a vedação do silo para que haja a fermentação. É um alimento volumoso, usado principalmente para bovinos. Na época seca ela pode substituir o pasto. Na engorda em confinamento ela é usada junto com os grãos e farelos (CARDOSO; SILVA, 1995).

Para o desempenho desejável dos animais confinados, há a necessidade de uma alimentação de boa qualidade. O uso de ensilagens para a alimentação de animais nos períodos de carência de pastagens, bem como para a engorda de animais tem se tornado prática comum entre os pecuaristas. O milho (Zea mays L.) é a espécie forrageira mais utilizada para esta finalidade (ALMEIDA et al. 1995; GENRO; QUADROS; COELHO, 1995).

Segundo Coelho; França (2004) a cultura das mais tradicionais, o milho ocupa posições significativas quanto ao valor de produção agropecuária, área cultivada e volume produzido, especialmente nas regiões Sul, Sudeste e Centro-Oeste do Brasil. Apesar do alto potencial produtivo, da cultura do milho, evidenciada por produtividades de 10 e 70 t/ha de grãos e forragem respectivamente, obtidas tanto em condições experimentais como por agricultores que adotam tecnologias adequadas, o que se observa na prática são produtividades da ordem de 2 a 3 t/ha de grãos e 10 a 45 t de massa verde/ha.

Flaresso; Gross; Almeida (2000) avaliaram cultivares de milho onde os mais tardios apresentaram maior altura que os mais precoces, enquanto, em relação ao número de espigas por planta, observou-se igualdade, com valores próximos a um. Com relação às frações das plantas de milho, os materiais mais precoces apresentaram em torno de $30 \%$ de colmo em sua composição, contra $35 \%$ de materiais mais tardios e mais altos. No que diz respeito à participação das folhas, observaram-se em torno de $18 \%$. A proporção de espiga componente mais importante para produção de silagem de alta energia destacou-se nos precoces variando de 47 a $42,4 \%$, nos tardios de 41,4 a 38,6\%.

No âmbito nacional, a cultura do milho pode ser considerada a mais importante, tanto sob o aspecto econômico quanto social. O milho é uma cultura muito utilizada para confecção de silagem no Brasil, por apresentar pronunciada expressão no rendimento de massa verde por unidade de área e excelente qualidade de fermentação e manutenção do valor nutritivo da massa 
ensilada, conferindo baixo custo operacional de produção, além da boa aceitabilidade por parte dos bovinos. O sucesso na produção de silagem, todavia, depende do grau de adaptação dos diferentes genótipos frente às características edafoclimáticas da área de cultivo (ALVES FILHO; RESTLE; BRONANI, 2000).

Para Bezerra; Tiesenhausen; Oliveira (1993) entre as forrageiras utilizadas como propósito de ensilagem, o milho é que mais se destacou, sobretudo em razão de seu valor nutritivo e de boa produção de massa por unidade de área plantada. Para esta prática, o milho (Zea mays, L.) é recomendado, tornando-se a espécie padrão, com valor nutritivo tomado como referência.

Nas condições tropicais, o desempenho de bovinos, tanto para corte como leite, situa-se abaixo do seu potencial genético, devido à qualidade inferior das forrageiras tropicais e do efeito negativo do clima sobre a disponibilidade de forragem e de nutrientes das pastagens tropicais. As forrageiras mais comumente usadas, dos gêneros Brachiaria e Panicum, fornecem apenas entre $30 \%$ e $50 \%$ das exigências nutricionais diárias dos animais em pastejo, por apresentarem forragem com baixos teores de proteína e carboidratos solúveis, bem como alto teores de fibra. Nessa situação, o desempenho animal é influenciado, principalmente, pela baixa ingestão de proteína e energia, o que é agravado pela disponibilidade irregular de biomassa durante o ano. Se o objetivo da pecuária de corte for reduzir o ciclo de produção, há necessidade de alternativas forrageiras que complementem essas deficiências. É uma boa alternativa para tal o milheto (KICHEL; MIRANDA, 2000).

O milheto (Pennisetum glaucum) é oriundo da África Tropical Central, estando amplamente distribuído nas regiões tropicais mais secas, pois tem elevada tolerância as baixas pluviosidades. No Rio Grande do Sul é semeado na primavera/verão. A produção de silagem na região de clima temperado tem sido feita, prioritariamente, com as culturas de milho e sorgo devido ao seu alto rendimento de matéria seca por hectare e ao elevado teor de carbohidratos solúveis o que proporciona uma boa qualidade do material ensilado. Uma alternativa para a confecção de silagem é o milheto, que em outras regiões do país vem apresentando, segundo a literatura, uma boa qualidade e produção de matéria seca (RODRIGUES, 2002).

Apesar de apresentar ampla capacidade de adaptação, melhor conhecimento das características da planta de milheto é fator importante para a expansão e aproveitamento correto da cultura, pois seu comportamento pode variar em função das diferentes condições ambientais. A época de semeadura do milheto varia de região para região, podendo, em locais tropicais, ser semeado continuamente (ALCÂNTARA; BUFARAH, 1988).

Nucleus, v.6, n.2, out. 2009 
Segundo Kichel; Miranda (2000) o milheto é uma forrageira de clima tropical, anual, de hábito ereto, porte alto, com desenvolvimento uniforme e bom perfilhamento, e produção de sementes entre $500 \mathrm{~kg} / \mathrm{ha}$ e $1.500 \mathrm{~kg} / \mathrm{ha}$. Apresenta excelente valor nutritivo (até $24 \%$ de proteína bruta quando em pastejo), boa palatabilidade e digestibilidade (60\% a 78\%) em pastejo, sendo atóxica aos animais em qualquer estádio vegetativo. Quanto ao potencial produtivo de forragem, pode alcançar até 60 toneladas de massa verde e 20 toneladas de matéria seca por hectare, quando cultivado no início da primavera.

Para uma eficiente germinação das sementes, é necessário que a temperatura média do solo seja superior a $20^{\circ} \mathrm{C}$, além de haver umidade suficiente para a emergência das plântulas. Por isso, o milheto pode ser semeado no início da primavera, por ocasião das primeiras chuvas, até início do outono: a semeadura poderá ser efetuada a lanço ou em linha, sendo que de preferência deve-se utilizar a semeadura em linha. Utilizam-se $18 \mathrm{~kg}$ a $20 \mathrm{~kg}$ de semente/ha, com espaçamento de $20 \mathrm{~cm}$ a $30 \mathrm{~cm}$ entre linhas para utilização em pastejo. Ou 12 a $15 \mathrm{~kg} / \mathrm{ha}$, com espaçamento entre linhas de $40 \mathrm{~cm}$ a $60 \mathrm{~cm}$ para produção de grãos, sementes ou silagem. A profundidade de semeadura pode variar de $2 \mathrm{~cm}$ a $4 \mathrm{~cm}$. Para semeadura a lanço utiliza-se $20 \%$ a mais de semente/ha. No caso de sobressemeadura em lavouras de soja, milho, sorgo, arroz etc., utiliza-se de $30 \mathrm{~kg}$ a $35 \mathrm{~kg}$ de sementes/ha (MILHETO, 2008).

Outras culturas, por se adaptarem as condições climáticas e de solo menos favoráveis, têm sido recomendadas, como o sorgo (Sorghum bicolor (L). Moench) e o girassol (Helianthus annus L.) (ALMEIDA et al.,1995; GENRO; QUADROS; COELHO, 1995).

O uso do sorgo para silagem no Brasil começou com a introdução de variedades de porte alto, com alta produtividade de massa e normalmente com elevados teores de açúcar. A cultura do sorgo para silagem, de modo geral, tem apresentado produções de MS mais elevadas que a do milho, especialmente em condições marginais de cultivo, como aquelas de regiões de solos de fertilidade natural mais baixa e locais onde a ocorrência de estiagens longas são freqüentes. (ZAGO, 1991).

As folhas de sorgo apresentam alta digestibilidade, mas seus grãos devido ao alto conteúdo de tanino apresentam baixa digestibilidade. Caules com uma alta proporção de parede celular são de baixa digestibilidade. Portanto, o valor nutritivo da silagem pode ser melhorado com a diminuição da proporção de caules na sua constituição. De maneira geral, as silagens de sorgo, têm sido reputadas como apresentando de 85 a $90 \%$ do valor nutritivo da silagem de milho. Atualmente tem-se procurado desenvolver híbridos que tenham um bom equilíbrio entre 
colmo, folhas e panícula, objetivando-se obter boas produtividades com bom valor nutritivo (ZAGO, 1991).

O sorgo é uma cultura promissora, devido ao sistema radicular desenvolvido e outras características relacionadas à resistência à seca (Alvarenga, 1994), sendo favorecido seu cultivo na safrinha, com menores riscos do que na cultura do milho.

Segundo Zago (1991), a tolerância à seca faz do sorgo uma das espécies preferidas para o cultivo na safrinha. Além disso, possui capacidade produtiva e valor nutritivo elevados e possibilidade de aproveitamento da rebrota, com produção de até $60 \%$ do primeiro corte.

O girassol (Helianthus annus L.) é uma alternativa para silagem, pois se desenvolve bem em climas temperados, subtropical e tropical. Possui, também, maior tolerância à deficiência hídrica e geadas leves, quando comparado com o milho e o sorgo. A silagem de girassol apresenta como vantagens o alto valor energético e o teor de proteína, que pode ser $35 \%$ superior ao do milho (GONÇALVES; TOMICH, 2000).

Para Gonçalves; Costa (2008) o espaçamento ideal varia de 80 a 90 centímetros entre linhas, variando a população ideal de 40.000 a 45.000 plantas por hectare (4 plantas por metro) no final do ciclo, conforme o híbrido ou cultivar. O consumo médio de sementes varia de 3,5 a 4,0 quilos por hectare.

O girassol é caracterizado por apresentar maior resistência ao frio e ao calor que a maioria das culturas, além de apresentar ampla adaptabilidade às diferentes condições edafoclimáticas. Sua capacidade de extrair água disponível na camada de zero a dois metros de profundidade foi estimada em aproximadamente 92\%, contra 64\% do sorgo (BREMNER; PRESTON; GROTH, 1986), sendo capaz de tolerar períodos secos e produzir grande quantidade de matéria seca (SHEAFFER; MCNEMAR; CLARK et al., 1977). Graças a essas características, o girassol se destaca como nova opção nos sistemas de rotação e sucessão de culturas (CASTRO; CASTIGLIONI; BALLA, 1993). Assim, o uso do girassol na alimentação animal sob a forma de silagem tem surgido como boa alternativa para o Brasil devido aos períodos de déficit hídrico, que impossibilitam a produção de alimentos volumosos de boa qualidade e, conseqüentemente, a manutenção da produção animal todo o ano.

No Brasil, o girassol (Helianthus annuus, L.) tem sido objeto de muitas pesquisas na área da fisiologia vegetal, em razão do elevado potencial fotossintético, das altas taxas de crescimento, da capacidade em extrair e conduzir a água e dos movimentos diaeliotrópicos das folhas e do capítulo, porém, poucos estudos são feitos envolvendo a produção de girassol para ensilagem (CASTRO; CASTIGLIONI; BALLA, 1993). 


\section{MATERIAL E MÉTODOS}

O experimento foi instalado em área experimental, no Campus da Faculdade "Dr. Francisco Maeda”, localizado no município de Ituverava-SP, situado a $20^{\circ} 20^{\prime} 30^{\prime}$ ' de latitude S e $47^{\circ} 47^{\prime} 30^{\prime}$ ' de longitude W, estando a uma altitude de 631 metros, no período de 14 de novembro de 2007 a 12 de fevereiro de 2008.

O solo foi preparado de maneira convencional, usando-se uma aração, seguida de uma gradagem leve para eliminar os torrões e uniformizar o terreno e os sulcos foram abertos com a enxada.

Os tratos culturais realizados foram: uma gradagem leve antes do plantio para eliminar as plantas daninhas e uniformizar o terreno e um raleio 23 dias após o plantio.

O plantio das culturas foi realizado em 14 de novembro de 2007. Os espaçamentos foram de 0,$5 ; 0,6 ; 0,7$ e 0,8 metros entre linhas e uma distribuição de sementes de 60.000 plantas/ha do milho e girassol e 120.000 plantas/ha do milheto e sorgo.

$\mathrm{O}$ delineamento experimental foi o de blocos ao acaso em um esquema fatorial 4 x 4 com duas repetições, sendo cada parcela constituída por três metros lineares, com espaçamentos de $0,50,0,60,0,70$ e 0,80 metros.

Os dados coletados foram submetidos à análise de variância através do programa ESTAT e comparação das médias pelo teste de Tukey, tendo-se estabelecido o nível de 5\% de possibilidade de erro (95\% de confiança) para aceitação dos resultados.

A quantidade de matéria seca foram obtidas através do peso total de todas as folhas, colmos, espigas, panículas e capítulos, contidas nas duas linhas centrais. Com esses dados foi estimado o rendimento em toneladas por hectare.

\section{RESULTADOS E DISCUSSÃO}

As médias de peso de colmo, espiga/panícula/capítulo, folha e peso total de matéria verde (PTMV) nas culturas de girassol, milheto, milho e sorgo, são mostradas na Tabela 1. 
TABELA 1 - Produção de colmos, espigas, folhas e total de matéria verde de acordo com a cultura, Ituverava, SP, 2008.

\begin{tabular}{lllll}
\hline Cultura & $\begin{array}{l}\text { Peso } \\
\text { Colmo } \\
\end{array}$ & $\begin{array}{l}\text { Peso } \\
\text { Espiga/Panícula/Capítulo }\end{array}$ & $\begin{array}{l}\text { Peso } \\
\text { Folha }\end{array}$ & PTMV \\
& $35.551,47 \mathrm{a}$ & $27.328,00 \mathrm{a}$ & $\mathbf{K g})$ & $\mathbf{( K g )}$ \\
\hline Girassol & $25.554,22 \mathrm{~b}$ & $20.881,24 \mathrm{~b}$ & $6.875,59 \mathrm{c}$ & $69.775,06 \mathrm{a}$ \\
Milheto & $19.293,73 \mathrm{c}$ & $3.685,68 \mathrm{c}$ & $5.858,25 \mathrm{~d}$ & $33.784,07 \mathrm{c}$ \\
Milho & $27.302,21 \mathrm{~b}$ & $2.371,22 \mathrm{c}$ & $10.844,01 \mathrm{a}$ & $51.018,99 \mathrm{~b}$ \\
Sorgo & $26.925,41$ & $13.566,54$ & $8.196,49 \mathrm{~b}$ & $39.184,38 \mathrm{c}$ \\
\hline Média Geral & 11,31 & 13,46 & $7.943,59$ & $48.435,62$ \\
CV\% & & 7,86 & 10,18
\end{tabular}

Médias seguidas de mesma letra, na coluna, não diferem estatisticamente (Tukey a 5\%).

Os resultados foram significativos para o peso do colmo $(35.551,47 \mathrm{Kg})$, peso do capítulo $(27.328,00 \mathrm{Kg}$ ) e peso total de matéria verde (PTMV) com $69.775,06 \mathrm{Kg}$ na cultura do girassol. Já para o peso da folha observou-se diferença significativa para a cultura do milho com 10.844,01 $\mathrm{Kg}$.

Vieira (1999), analisando híbridos de milho para silagem, verificou médias de 8.330 $\mathrm{Kg} / \mathrm{ha}$ a $9.970 \mathrm{Kg} / \mathrm{ha}$ de folha em relação à produção total, inferior aos obtidos no presente trabalho.

Vieira (1999) verificou que as médias em relação à produção total foram de $16.000 \mathrm{Kg} / \mathrm{ha}$ a $19.220 \mathrm{Kg} / \mathrm{ha}$ de colmo, inferiores as encontradas neste experimento.

Rodrigues Junior (1999), avaliando cinco cultivares de milho para a produção de silagem, encontrou produções de colmo de $7.000 \mathrm{Kg} / \mathrm{ha}$ a $17.200 \mathrm{Kg} / \mathrm{ha}$, bastante inferiores as obtidas neste trabalho.

Vieira (1999), avaliando híbridos de milho para silagem, obteve médias de matéria verde que variavam de $40.060 \mathrm{Kg} / \mathrm{ha}$ a $47.360 \mathrm{Kg} / \mathrm{ha}$, dados inferiores aos encontrados no presente experimento.

Cecato et al (1994) encontraram produção de massa verde de sorgo com valores entre 73.085 a $78.730 \mathrm{Kg} / \mathrm{ha}$, sendo superiores aos deste experimento. Chielle et al (1998) verificaram produção com $56.010 \mathrm{Kg} / \mathrm{ha}$, Denardini et al (1991) obtiveram produções que variavam de 29.053 a $41.091 \mathrm{Kg} / \mathrm{ha}$ de massa verde de sorgo, situando esses valores acima dos verificados neste experimento.

Almeida et al (1992) encontrou produções de girassol de $24.718 \mathrm{Kg} / \mathrm{ha}$ de massa verde em sistema de monocultivo e observou que a silagem de girassol confirmou ser mais uma alternativa Nucleus, v.6, n.2, out. 2009 
tanto protéica quanto energética na alimentação volumosa dos ruminantes, sendo os dados encontrados inferiores aos do presente trabalho.

Banys (1994) observou que a produção de massa verde de girassol foi em média 17.025 $\mathrm{Kg} / \mathrm{ha}$, produção esta considerada baixa, devido provavelmente ao baixo nível de fertilizantes utilizados na época de implantação do experimento, dados bastante inferiores aos obtidos no presente trabalho.

A Tabela 2 destaca a produção de colmos, espiga/panícula/capítulo, folha e peso total de matéria verde, das culturas de girassol, milheto, milho e sorgo de acordo com o espaçamento.

TABELA 2 - Produção de colmos, espigas, folhas e total de matéria verde de acordo com o espaçamento.

\begin{tabular}{lllll}
\hline Espaçamento & Peso & Peso & Peso & PTMV \\
& Colmo & $\begin{array}{l}\text { Espiga/Panícula/Capítulo } \\
(\mathbf{K g})\end{array}$ & $\begin{array}{l}\text { Folha } \\
(\mathbf{K g})\end{array}$ & $(\mathbf{K g})$ \\
\hline $\mathbf{0 , 5 0}$ & $\mathbf{K g})$ & $12.374,99 \mathrm{~b}$ & $7.666,66 \mathrm{~b}$ & $44.249,99 \mathrm{~b}$ \\
$\mathbf{0 , 6 0}$ & $24.208,33 \mathrm{~b}$ & $7.534,41 \mathrm{~b}$ & $46.317,58 \mathrm{ab}$ \\
$\mathbf{0 , 7 0}$ & $25.589,025 \mathrm{ab}$ & $13.193,91 \mathrm{ab}$ & $7.797,22 \mathrm{~b}$ & $49.997,49 \mathrm{ab}$ \\
$\mathbf{0 , 8 0}$ & $28.867,60 \mathrm{a}$ & $13.331,66 \mathrm{ab}$ & $8.776,04 \mathrm{a}$ & $53.177,45 \mathrm{a}$ \\
\hline
\end{tabular}

Médias seguidas de mesma letra, na coluna, não diferem estatisticamente (Tukey a 5\%).

Nos espaçamentos de 0,60, 0,70 e 0,80 metros, os pesos de colmo, espiga, panícula e PTMV não apresentam diferenças significativas. Já para o peso de folha, o espaçamento de 0,80 proporcionou melhor média.

Prata (2000) obteve produções de peso de folhas de milho de $6.468,80 \mathrm{Kg} / \mathrm{ha}, 6.656,30$ $\mathrm{Kg} / \mathrm{ha}, 7.531,30 \mathrm{Kg} / \mathrm{ha}$ e $7.750 \mathrm{Kg} / \mathrm{ha}$ nos espaçamentos de $0,50,0,60$, 0,70 e 0,80 metros respectivamente, dados inferiores ao obtido no presente trabalho.

Prata (2000) obteve médias para peso de espiga entre $16.780 \mathrm{Kg} / \mathrm{ha}$ e $16.062,5 \mathrm{Kg} / \mathrm{ha}$, superiores ao encontrado neste trabalho.

Prata (2000) quanto ao peso de colmo mais pendão nos diferentes espaçamentos avaliados, obteve médias de $17.938 \mathrm{Kg} / \mathrm{ha}$ e $17.469 \mathrm{Kg} / \mathrm{ha}$, inferiores ao encontrados no trabalho.

Prata (2000) com relação a produção de massa verde entre os híbridos, verificou produções nos espaçamentos de 0,80 metros de $42.469 \mathrm{Kg} / \mathrm{ha}$ e 0,70 metros de $41.063 \mathrm{Kh} / \mathrm{ha}$, valores inferiores aos obtidos no presente trabalho.

A Tabela 3 apresenta a produção de colmo, folhas e peso total de matéria verde de acordo com a interação cultura x espaçamento. 
TABELA 3 - Produção de colmos (P Colmo), folhas (P Folha) e total de matéria verde (PTMV) de acordo com a interação cultura x espaçamento.

\begin{tabular}{|c|c|c|c|c|}
\hline \multirow{4}{*}{ Cultura } & \multicolumn{4}{|c|}{ Características } \\
\hline & \multicolumn{4}{|l|}{ P Colmo } \\
\hline & \multicolumn{4}{|c|}{ Espaçamentos } \\
\hline & $\mathbf{0 , 5 0}$ & $\mathbf{0 , 6 0}$ & $\mathbf{0 , 7 0}$ & $\mathbf{0 , 8 0}$ \\
\hline Girassol & $28.166,66 \mathrm{c}$ & $31.526,51 \mathrm{bc}$ & $43.450,20 \mathrm{a}$ & $39.062,49 \mathrm{ab}$ \\
\hline Milheto & $22.333,33 \mathrm{a}$ & $23.471,28 \mathrm{a}$ & $27.974,79 \mathrm{a}$ & $28.437,50 \mathrm{a}$ \\
\hline Milho & $18.833,33 \mathrm{a}$ & $18.610,36 \mathrm{a}$ & $17.856,24 \mathrm{a}$ & $21.874,99 \mathrm{a}$ \\
\hline Sorgo & $27.499,99 \mathrm{a}$ & $28.748,84 \mathrm{a}$ & $26.189,16 \mathrm{a}$ & $26.770,83 \mathrm{a}$ \\
\hline Cultura & \multicolumn{4}{|l|}{ P Folha } \\
\hline Girassol & $5.166,66 \mathrm{c}$ & $6.666,39 \mathrm{bc}$ & $7.023,45 \mathrm{ab}$ & $8.645,83 \mathrm{a}$ \\
\hline Milheto & $5.333,33 \mathrm{a}$ & $5.138,68 \mathrm{a}$ & $6.190,16 \mathrm{a}$ & $6.770,83 \mathrm{a}$ \\
\hline Milho & $11.333,33 \mathrm{a}$ & $10.138,48$ a & $10.237,58 \mathrm{a}$ & $11.666,66 \mathrm{a}$ \\
\hline Sorgo & $8.833,33 \mathrm{a}$ & $8.194,11 \mathrm{a}$ & $8.020,83 \mathrm{a}$ & $7.757,70 \mathrm{a}$ \\
\hline Cultura & \multicolumn{4}{|l|}{ PTMV } \\
\hline Girassol & $56.333,32 \mathrm{c}$ & $64.580,74 \mathrm{bc}$ & $78.210,36 \mathrm{ab}$ & $79.895,82 \mathrm{a}$ \\
\hline Milheto & $29.666,66 \mathrm{a}$ & $31.109,85 \mathrm{a}$ & $36.545,78 \mathrm{a}$ & $37.813,99 \mathrm{a}$ \\
\hline Milho & $50.999,99 \mathrm{a}$ & $49.164,68$ a & $47.973,78 \mathrm{a}$ & $55.937,49 \mathrm{a}$ \\
\hline Sorgo & $39.999,97 \mathrm{a}$ & $40.415,03 \mathrm{a}$ & $37.260,03 \mathrm{a}$ & $39.062,49 \mathrm{a}$ \\
\hline
\end{tabular}

Médias seguidas de mesma letra, na linha, não diferem estatisticamente (Tukey a 5\%).

Quanto ao peso do colmo nas culturas de girassol, milheto, milho e sorgo nos espaçamentos de $0,50,0,60,0,70$ e $0,80 \mathrm{~m}$, obtiveram resultados significativos nos quatro espaçamentos a cultura do girassol registrando $28.166,66 \mathrm{Kg}, 31.526,51 \mathrm{Kg}, 43.450,20 \mathrm{Kg}$ e $39.062,49 \mathrm{Kg}$ respectivamente.

Quanto ao peso da folha nos quatro espaçamentos destacaram-se o milho e quanto ao peso total de matéria verde nos quatro espaçamentos foram significativos os resultados obtidos pela cultura de girassol. 


\section{CONCLUSÃO}

Pelo presente trabalho concluiu-se que a produção total de massa verde para a cultura do girassol, milheto e milho foi maior com o espaçamento de $0,80 \mathrm{~m}$, enquanto a cultura do sorgo a produção foi maior com o espaçamento de $0,60 \mathrm{~m}$.

\section{REFERÊNCIAS}

AGROINFO. O Fórum do agronegócio brasileiro. Fenação e silagem: a importância nos períodos e escassez. Disponível em: 〈http://agroinfo.com.br/showthread.php?t=148>. Acesso em: 22 ago. de 2008.

ALCÂNTARA, P. B.; BUFARAH, G. Plantas forrageiras: gramíneas e leguminosas. 4 ed. São Paulo: Nobel, 1988. 162p.

ALMEIDA, M. F., de. et al. Composição química e consumo voluntário das silagens de sorgo, em dois estádios de corte, girassol e milho para ruminantes. Ciência e Prática, Lavras, v.19, n.3, p.315-321, 1995.

ALVARENGA, M. C. V. Consumo e digestibilidade aparente de silagens de sorgo (Sorghum vulgare Pers) em três momentos de corte e dois tamanhos de partículas, em carneiros. 1994. 82p. Dissertação (Mestrado em Zootecnia)-Universidade Federal de Minas Gerais, Belo Horizonte, 1994.

ALVES FILHO, D.C. et al. Silagem de sorgo ou milho para terminação de novilhos em confinamento. In: REUNIÃO ANUAL DA SOCIEDADE BRASILEIRA DE ZOOTECNIA, 37. 2000, Viçosa, MG. Anais... Viçosa: SBZ, 2000. CD-ROM

BARBOSA, U. B. Avaliação da influência da altura de corte nas características do milho (Zea mays L.) para silagem. 2001. 29p. Trabalho de Conclusão de Curso. (Graduação em Agronomia) - Faculdade Dr. Francisco Maeda. Fundação Educacional de Ituverava.

BANYS, V. L. Consórcio de milho (Zea mays L.) e girassol (Helianthus annus L.): características agronômicas, composição química e degradabilidade. 1994. 61p. Tese (Mestrado) - Escola Superior de Agricultura de Lavras.

BEZERRA, E.S. et al. Valor nutricional das silagens de milho, milho associado com sorgo e rebrotas de sorgo. R. Soc. Bras. Zootec. v.22, n.6, p.1044-1054, 1993. 
BREMMER, P.M.; PRESTON, G.K.; GROTH, C.F. A field comparison of sunflower (Helianthus annus) and Sorghum (Sorghum bicolor) in along drying cycle. I. Water extration. Australian Journal of Agricultural Research, Cairo, v.37, n.5, p.483-493, 1986.

CARDOSO, E. G.; SILVA, J. M. da. Silos, silagem e ensilagem. Embrapa Gado de Corte. Campo Grande, MS, fev. n.2, 1995. Disponível em:

http://www.cnpgc.embrapa.br/publicacoes/divulga/GCD02.html >. Acesso em: 25 de out. de 2008.

CASTRO, C. et al. A cultura do girassol. Londrina: Embrapa-CNPSo, 1997. 36p. (Circular Técnica, 13)

CECATO, V. et al. Avaliação de híbridos de sorgo para produção de silagem. XXXI Reunião da Sociedade Brasileira de Zootecnia, de Maringá, PR. Anais... jul, 1994.

CHIELLE, Z. G. et al. Avaliação de cultivares de sorgo para silagem em solo hidromórfico. 1. Desempenho e produção. In: REUNIÃO DA SOCIEDADE BRASILEIRA DE ZOOTECNIA, 35. Botucatu. Anais... jul. 1998.

COELHO, A. M.; FRANÇA, G. E. Seja o doutor do seu milho. In: POTAFOS. Arquivo do Agrônomo. Piracicaba, n.2, p.01-09, 2004. Disponível em:<

http://www.ipni.org.br/ppiweb/brazil.nsf/87cb8a98bf72572b8525693e0053ea70/d5fbc829a2f542

98832569f8004695c5/\$FILE/Milho.pdf >. Acesso em: 25 de out. de 2008.

DENARDINI, R. B. N. et al. Avaliação de cultivares e híbridos de milho, sorgo e milheto para produção de silagem. In: REUNIÃO DA SOCIEDADE BRASILEIRA DE ZOOTECNIA, 28. João Pessoa, PB. Anais... jul. 1991.

FLARESSO, J.A.; GROSS, C.D.; ALMEIDA, E.X. Cultivares de milho (Zea mays L.) e sorgo (Sorghum bicolor (L.) Moench.) para ensilagem no Alto Vale do Itajaí, Santa Catarina. Revista Brasileira de Zootecnia, v.29, n.6, p.1608-1615, 2000.

GENRO, T.C.M. et al. Produção e qualidade de silagens de híbridos de milho (Zea mays) e de híbridos de sorgo (Sorghum bicolor). Ciência Rural, Santa Maria, v.25, n.3, p.461-464, 1995.

GONÇALVES, A. DE C.; COSTA, P. J. A. Silagem de girassol. Disponível em:<http://www.projepec.com.br/Silagem\%20de\%20girassol.pdf >. Acesso em: 25 de out. de 2008.

GONÇALVES, L.C.; TOMICH, T.R. Produção e utilização de silagem de girassol. In: SIMPÓSIO DE FORRAGICULTURA E PASTAGENS.-TEMAS EM EVIDÊNCIA, 2000, LAVRAS. Anais... Lavras: UFLA, 2000, p.203-236.

KICHEL, A. N.; MIRANDA, C. H. B._Uso do milheto como planta forrageira. Embrapa Gado de Corte. Campo Grande, MS, dez. n. 46, 2000. Disponível em: <

http://www.cnpgc.embrapa.br/publicacoes/divulga/GCD46.html>. Acesso em: 25 de out. de 2008. 
MILHETO. Semeadura. Disponível em:<http://www.maxiagrors.com.br/index.php?id=2,9,0,0,1,0> . Acesso em: 25 de out. de 2008.

POSSENTI, R. A. Parâmetros bromatológicos e fermentativos das silagens de milho e girassol. Ciência Rural, Santa Maria, v.35, n.5, p.1185-1189, 2005.

PRATA, A. de P. F. Avaliação da produtividade e qualidade de híbrido de milho (Zea mays L.) para silagem sob diferentes espaçamentos. 2000. 25p. Trabalho de Conclusão de Curso. (Graduação em Agronomia) - Faculdade Dr. Francisco Maeda. Fundação Educacional de Ituverava.

RIBEIRO, E. L. de A. et al. Silagens de girassol (Helianthus annus L.), milho (Zea mays L.) e sorgo (Sorghum bicolor (L.) Moench) para ovelhas em confinamento. Ciência Rural, Santa Maria, v.32, n.2, p.299-302, 2002.

RODRIGUES JÚNIOR, C. Avaliação de cultivares de milho (Zea mays L.) para produção de silagem de espiga. 1999. 23p. Trabalho (Graduação em Agronomia). Faculdade Dr. Francisco Maeda. Fundação Educacional de Ituverava.

RODRIGUES, R. C. Avaliação bromatológica de silagem pré-secada de milheto (Pennisetum glaucum), em três estádios fenológicos e três tempos de emurchecimento. Pelotas, 2002. (Comunicado técnico, 65)

SHEAFFER, C.C.; McNEMAR, J.H.; CLARK, N.A. Potential of sunflowers for silage in doublecropping systems following small grains. Agron. J., v.69, p.543-546, 1977.

VIEIRA, L. D. R. Avaliação de diferentes híbridos para produção e qualidade de silagem de milho (Zea mays L.). 1999. 24p. Trabalho (Graduação em Agronomia). Faculdade Dr. Francisco Maeda. Fundação Educacional de Ituverava.

ZAGO, C. P. Cultura do sorgo para produção de silagem de alto valor nutritivo. In: SIMPÓSIO SOBRE NUTRIÇÃO DE BOVINOS, 4., 1991, Piracicaba. Anais... Piracicaba: FEALQ, 1991. p. 169-218. 
